\title{
АНАЛОГ СТАНУ КОГЕРЕНТНОГО ПОЛОНЕННЯ НАСЕЛЕНОСТЕЙ У ПОЛІХРОМАТИЧНОМУ ПОЛІ
}

\author{
B.I. РОМАНЕНКО, ${ }^{1}$ О.В. РОМАНЕНКО ${ }^{2}$ Л.П. ЯЦЕНКО ${ }^{1}$ \\ ${ }^{1}$ Інститут фізики НАН України \\ (Просn. Науки, 46, Київ 03028; e-mail: vr@iоp. kiev. ua) \\ ${ }^{2}$ Київський національний університет ім. Тараса Шевченка \\ (Просп. Академіка Глушкова, 2, Київ 03022)
}

УДК 535.372

(c) 2011

\begin{abstract}
Теоретично досліджено взаємодію трирівневого атома з поліхроматичним полем з еквідістантними спектральними компонентами ( $\Lambda$-схема взаємодії з полем). Показано, що взаємодія атома з таким полем зводиться до взаємодії з біхроматичним полем з додатковими світловими зсувами частот переходів і додатковим, пропорційним інтенсивності поля, зв'язком нижніх рівнів атома. Наявність цього зв'язку дозволяє говорити про когерентне полонення населеності лише наближено, оскільки у загальному випадку довільних дипольних моментів переходів темний стан не є власним станом ефективного гамільтоніана. Розглянута модель дає просту теоретичну інтерпретацію формування близького до когерентного полонення населеностей стану атома у полі випромінювання фемтосекундного лазера.
\end{abstract}

\section{1. Вступ}

Явище когерентного полонення населеностей (КПН) [1-5] лежить в основі електромагнітноіндукованої прозорості [6-9], перенесенні населеностей між станами атомів і молекул за допомогою стимульованого раманівського адіабатичного проходження (СТИРАП) [10-13], малогабаритних квантових лазерних стандартів частоти [14]. Воно є підгрунтям одного з методів охолодження атомів до наднизьких температур [15].

У найпростішому випадку когерентне полонення населеності проявляється при взаємодії трирівневого атома з біхроматичним випромінюванням, коли кожна зі спектральних компонент пов'язує один з двох метастабільних (один з них може бути стабільним) станів атома зі збудженим ( $\Lambda$-схема взаємодії атома 3 полем). Тоді при реєстрації інтенсивності флуоре- сценції, залежно від частоти однієї зі спектральних компонент, спостерігається вузький провал (темний резонанс), коли різниця частот компонент близька до частоти переходу між довгоживучими станами атома. Фізично когерентне полонення населеності грунтується на існуванні в атомі "темного стану" - суперпозиції довгоживучих станів, яка визначається співвідношенням інтенсивностей спектральних компонент, перебуваючи у якому атом не поглинає випромінювання.

Останнім часом зростає інтерес до темних резонансів у поліхроматичному полі з еквідистантними компонентами спектра [16-20]. Темний резонанс виникає у випадку, коли частота переходу між довгоживучими станами атома кратна різниці частот сусідніх спектральних компонент поля. Такі резонанси спостерігалися при збудженні атомів випромінюванням фемтосекундного лазера [20], а резонанс електромагнітно-індукованої прозорості (в основі якого лежить явище КПН) у роботі [17] зареєстровано в полі послідовності світлових імпульсів пікосекундного лазера з синхронізацією мод. Також темний резонанс з близькою до 100\% контрастністю спостерігався в парі натрію у полі випромінювання багатомодового лазера в режимі вільної генерації [16].

Ми проаналізуємо взаємодію трирівневої системи 3 поліхроматичним полем низької інтенсивності, нехтуючи релаксаційними процесами, і покажемо, що поліхроматична взаємодія зводиться до біхроматичної, але $з$ залежним від поля зсувом частот переходів в атомі. Крім того, буде показано, що у загальному випадку довільних дипольних моментів переходів про когерентне полонення населеності можна говорити 


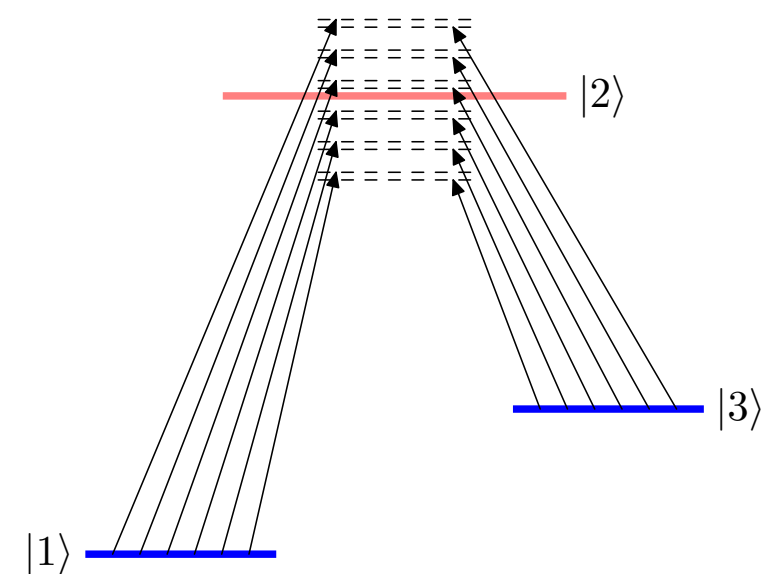

Рис. 1. Схема взаємодії трирівневого атома з поліхроматичним полем. Різниця частот сусідніх спектральних компонент дорівнює $\varpi$

лише наближено, оскільки темний стан не є власним станом ефективного гамільтоніана - найближчий до "темного" стану власний стан ефективного гамільтоніана майже завжди має невелику домішку збудженого стану. Теоретичний аналіз резонансів когерентного полонення населеностей у поліхроматичному полі лазера зі зсунутим за частотою зворотним зв'язком [21] вже проведено нами методом теорії збурень для матриці густини з урахуванням однорідного та неоднорідного розширення спектральних ліній випромінювання атомів в оточенні буферного газу [22]. Це дослідження хоч і дозволяє отримати вирази для світлових зсувів частот переходів, зумовлених великою кількістю спектральних компонент, проте залишає поза увагою фізичну суть резонансу КПН в поліхроматичних полях, а саме, формування непоглинаючого, точніше, малопоглинаючого стану. Для висвітлення цього питання слід знайти вигляд ефективного гамільтоніана, зумовленого дією дуже слабких, але багаточисельних спектральних компонент поля.

В основі нашого аналізу лежить усереднення за оберненою частотною різницею сусідніх спектральних компонент - це найменший характерний час $\tau$ задачі. Іншими словами, ми проводимо усереднення за швидким рухом системи. Для руху частинки у швидкозмінному полі відповідний формалізм викладено у [23]. Його модифікацію для дворівневої квантово-механічної системи використовували для розрахунку сили світлового тиску на атом у частотномодульованому полі [24] та при розрахунку пастки для атомів, в основі якої лежить взаємодія атома із зустрічними імпульсами [25]. $\mathrm{y}$ розділі 2 наведено основні рівняння, необхідні для опису взаємодії атома з полем. Розділ 3 містить виведення ефективного гамільтоніана, який відповідає за повільну, з характерним часом, більшим за $\tau$, зміну амплітуд імовірності перебування атома в одному зі станів. Світлові зсуви частот переходів та зв'язок метастабільних станів, зумовлений поліхроматичністю поля, на прикладі гаусового розподілу інтенсивності за спектром розглянуто в розділі 4. У розділі 5 знайдено один із власних станів ефективного гамільтоніана, який є аналогом стану когерентного полонення населеності у випадку поліхроматичного поля. Резонанси когерентного полонення населеності у поліхроматичному полі з урахуванням релаксаційних процесів досліджено в розділі 6. У розділі 7 коротко підсумовано отримані результати.

\section{2. Основні рівняння}

Розглянемо трирівневий атом з двома метастабільними станами $|1\rangle$ i $|3\rangle$ та збудженим станом $|2\rangle$, що взаємодіє з поліхроматичним полем з еквідистантними частотами (див. рис. 1). Різниця частот сусідніх спе-

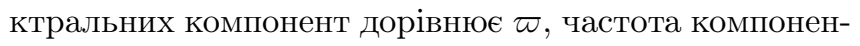
ти 3 максимальною інтенсивністю дорівнює $\omega$.

Електричне поле $\mathcal{E}(t)$ в точці перебування атома має вигляд

$\mathcal{E}(z, t)=\frac{\varepsilon \mathcal{E}_{0}}{2} \sum_{n=-\infty}^{\infty} a_{n} \exp \left[-i(\omega+n \varpi) t-i \varphi_{n}\right]+$ c.c.

Тут $\varepsilon$ - одиничний вектор поляризації, $\mathcal{E}_{0}-$ амплітуда спектральної компоненти 3 максимальною інтенсивністю, $a_{n}$ - відносні амплітуди спектральних компонент. Ми нормуємо відносні амплітуди $a_{n}$ так, щоб компонента $3 n=0$ мала максимальну амплітуду $a_{0}=1$. Виберемо для моделювання реалістичні відносні амплітуди у вигляді

$a_{n}=\exp \left(-\frac{n^{2}}{2 n_{0}^{2}}\right)$.

У наближенні обертової хвилі [26] взаємодія трирівневого атома з полем описується гамільтоніаном

$\mathcal{H}=\frac{\hbar}{2}\left[\begin{array}{ccc}-2 \delta_{1} & \Omega_{1}^{*}(t) & 0 \\ \Omega_{1}(t) & 0 & \Omega_{3}(t) \\ 0 & \Omega_{3}^{*}(t) & -2 \delta_{3}\end{array}\right]$

Тут $\delta_{1}=\omega_{12}-\omega-n_{1} \varpi-$ відстроювання найближчої до частоти $\omega_{12}$ переходу $|1\rangle \rightarrow|2\rangle$ спектральної компоненти лазерного випромінювання з частотою $\omega+n_{1} \varpi$ 
від $\omega_{12}$, а $\delta_{3}=\omega_{32}-\omega-n_{3} \varpi-$ відстроювання найближчої до частоти $\omega_{32}$ переходу $|3\rangle \rightarrow|2\rangle$ спектральної компоненти лазерного випромінювання з частотою $\omega+n_{3} \varpi$ від $\omega_{32}$. Частоти Рабі $\Omega_{1}(t), \Omega_{3}(t)$, присутні в (3), вводяться співвідношеннями

$\Omega_{j}(t)=\Omega_{j 0} \sum_{n} a_{n} \exp \left[i\left(n_{j}-n\right) \varpi t-i \varphi_{n}\right]$,

де $j=1,3 ; \Omega_{j 0} \equiv-\left(\boldsymbol{\varepsilon} \cdot \boldsymbol{d}_{j 2}\right) \mathcal{E}_{0} / \hbar$, а $\boldsymbol{d}_{j 2}-$ матричний елемент дипольного моменту (вибраний так, щоб $\left.\Omega_{j 0}>0\right)$.

\section{3. Ефективний гамільтоніан}

Будемо вважати, що

$\Omega_{10}, \Omega_{30},\left|\delta_{1}\right|,\left|\delta_{3}\right| \ll \varpi$.

Таким чином, розглядаємо випадок настільки великої різниці частот $\varpi$ сусідніх спектральних компонент поля, що збудження атома відбувається лише двома компонентами з відносними амплітудами $a_{n_{1}}$, $a_{n_{3}}$, частоти яких близькі відповідно до частот переходів $\omega_{12}$ і $\omega_{32}$, а решта спектральних компонент приводять до світлового зсуву резонансних частот. Еволюція хвильової функції характеризується двома часовими масштабами. Швидкий рух відбувається з характерним часом $\varpi^{-1}$, а повільний рух визначається малими характерними частотами задачі (див. (5)). Щоб отримати рівняння, що описує повільну зміну амплітуд імовірності, використаємо стандартну процедуру усереднення, описану в [23] для випадку механічного руху в полі з швидко осцилюючою силою.

Запишемо частоти Рабі (4) у вигляді суми двох доданків, перший з яких від часу не залежить, а другий

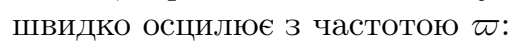

$\Omega_{j}(t)=\Omega_{j, s}(t)+\Omega_{j, f}, \quad j=1,3$,

де

$\Omega_{j, s}(t)=\Omega_{j 0} a_{n_{j}} e^{-i \varphi_{n_{j}}}$,

$\Omega_{j, f}(t)=\Omega_{j 0} \sum_{n \neq 0} a_{n+n_{j}} \exp \left[-i n \varpi t-i \varphi_{n+n_{j}}\right]$.

Ми очікуємо, що амплітуди імовірності станів атома можна записати у вигляді суми двох доданків, причому другий (малий порівняно з першим) швидко осцилює:

$C_{i}=\tilde{C}_{i}+c_{i}, \quad i=1,2,3$.
3 рівняння Шредінгера

$i \hbar \frac{d}{d t}\left(\begin{array}{l}C_{1} \\ C_{2} \\ C_{3}\end{array}\right)=\mathcal{H}\left(\begin{array}{l}C_{1} \\ C_{2} \\ C_{3}\end{array}\right)$

отримуємо

$i \dot{\tilde{C}}_{1}+\underline{i \dot{c}_{1}}=-\delta_{1} \tilde{C}_{1}-\underline{\delta_{1} c_{1}}+\frac{1}{2} \Omega_{1, s}^{*} \tilde{C}_{2}+$

$+\underline{\frac{1}{2} \Omega_{1, f}^{*} c_{2}}+\frac{1}{2} \Omega_{1, f}^{*} \tilde{C}_{2}+\underline{\frac{1}{2} \Omega_{1, s}^{*} c_{2}}$,

$i \dot{\tilde{C}}_{2}+\underline{i \dot{c}_{2}}=\frac{1}{2} \Omega_{1, s} \tilde{C}_{1}+\frac{1}{2} \Omega_{3, s} \tilde{C}_{3}+$

$+\underline{\underline{\frac{1}{2}} \Omega_{1, f} c_{1}}+\frac{1}{2} \Omega_{1, f} \tilde{C}_{1}+\frac{1}{2} \Omega_{1, s} c_{1}+$

$+\underline{\underline{\frac{1}{2}} \Omega_{3, f} c_{3}}+\frac{1}{2} \Omega_{3, f} \tilde{C}_{3}+\frac{1}{2} \Omega_{3, s} c_{3}$,

$i \dot{\tilde{C}}_{3}+\underline{i \dot{c}_{3}}=-\delta_{3} \tilde{C}_{3}-\underline{\delta_{3} c_{3}}+\frac{1}{2} \Omega_{3, s}^{*} \tilde{C}_{2}+$

$+\underline{\underline{1}} \Omega_{3, f}^{*} c_{2}+\frac{1}{2} \Omega_{3, f}^{*} \tilde{C}_{2}+\underline{\frac{1}{2} \Omega_{3, s}^{*} c_{2}}$.

Підкреслені доданки швидко осцилюють і дають нуль після усереднення за період осциляцій $2 \pi / \varpi$. Двічі підкреслені доданки складаються з добутків осцилюючих множників. Їх можна подати у вигляді суми повільно змінної з часом частини і швидко осцилюючої частини з нульовим середнім значенням. Щоб виключити швидкий рух, постулюємо, що обидва типи часових залежностей, швидка і повільна, справа і зліва у рівняннях (11)-(13) прирівнюються незалежно [23]. Осцилюючі частини рівнянь (11)-(13) дають

$i \dot{c}_{1}=\frac{1}{2} \Omega_{1, f}^{*} \tilde{C}_{2}$,

$i \dot{c}_{2}=\frac{1}{2} \Omega_{1, f} \tilde{C}_{1}+\frac{1}{2} \Omega_{3, f} \tilde{C}_{3}$

$i \dot{c}_{3}=\frac{1}{2} \Omega_{3, f}^{*} \tilde{C}_{2}$ 
Тут ми врахували, що $\left|c_{i}\right| \ll 1,\left|\dot{c}_{i}\right| \sim \varpi c_{i}$, нерівності (5) і знехтували малими доданками.

Повільно змінні з часом частини рівнянь (11)-(13) дають

$i \dot{\tilde{C}}_{1}=-\delta_{1} \tilde{C}_{1}+\frac{1}{2} \Omega_{1, s}^{*} \tilde{C}_{2}+\frac{1}{2}\left\langle\Omega_{1, f}^{*} c_{2}\right\rangle$,

$i \dot{\tilde{C}}_{2}=\frac{1}{2} \Omega_{1, s} \tilde{C}_{1}+\frac{1}{2}\left\langle\Omega_{1, f} c_{1}\right\rangle+\frac{1}{2} \Omega_{3, s} \tilde{C}_{3}+\frac{1}{2}\left\langle\Omega_{3, f} c_{3}\right\rangle$,

$i \dot{\tilde{C}}_{3}=-\delta_{3} \tilde{C}_{3}+\frac{1}{2} \Omega_{3, s}^{*} \tilde{C}_{2}+\frac{1}{2}\left\langle\Omega_{3, f}^{*} c_{2}\right\rangle$

де $\langle\cdots\rangle$ означає усереднення за часом на часовому проміжку $2 \pi / \varpi$.

Розв'язок рівнянь (14)-(16) має вигляд

$c_{1}=-\tilde{C}_{2} \Omega_{10} \sum_{n \neq 0} \frac{a_{n+n_{1}}}{2 n \varpi} \exp \left[i n \varpi t+i \varphi_{n+n_{1}}\right]$,

$c_{2}=\tilde{C}_{1} \Omega_{10} \sum_{n \neq 0} \frac{a_{n+n_{1}}}{2 n \varpi} \exp \left[-i n \varpi t-i \varphi_{n+n_{1}}\right]+$

$+\tilde{C}_{3} \Omega_{30} \sum_{n \neq 0} \frac{a_{n+n_{3}}}{2 n \varpi} \exp \left[-i n \varpi t-i \varphi_{n+n_{3}}\right]$

$c_{3}=-\tilde{C}_{2} \Omega_{30} \sum_{n \neq 0} \frac{a_{n+n_{3}}}{2 n \varpi} \exp \left[i n \varpi t+i \varphi_{n+n_{3}}\right]$

Підстановка $c_{i}$ в (17)-(19) дає рівняння для повільно змінних амплітуд, які мають вигляд рівняння Шредінгера з ефективним гамільтоніаном:

$\mathcal{H}_{e f f}=\frac{\hbar}{2}\left[\begin{array}{ccc}-2 \delta_{1}+S_{1} & \Omega_{1, s}^{*} & R \\ \Omega_{1, s} & -S_{1}-S_{3} & \Omega_{3, s} \\ R^{*} & \Omega_{3, s}^{*} & -2 \delta_{3}+S_{3}\end{array}\right]$.

Тут вирази

$S_{1}=\frac{\Omega_{10}^{2}}{2 \varpi} \sum_{n \neq 0} \frac{\left|a_{n+n_{1}}\right|^{2}}{n}$,

$S_{3}=\frac{\Omega_{30}^{2}}{2 \varpi} \sum_{n \neq 0} \frac{\left|a_{n+n_{3}}\right|^{2}}{n}$

відповідають за світлові зсуви частот переходів $|1\rangle \rightarrow$ $|2\rangle$ i $|3\rangle \rightarrow|2\rangle$. Ці зсуви визначаються спектральними компонентами лазерного випромінювання, відмінними від $n_{1}$ для переходу $|1\rangle \rightarrow|2\rangle$ і від $n_{3}$ для переходу $|3\rangle \rightarrow|2\rangle$, а зв'язок між станами $|1\rangle$ і $|3\rangle$ визначається коефіцієнтом

$R=\frac{\Omega_{10} \Omega_{30}}{2 \varpi} \sum_{n \neq 0} \frac{a_{n+n_{1}} a_{n+n_{3}}}{n} \exp \left(i \varphi_{n+n_{1}}-i \varphi_{n+n_{3}}\right)$

розмірності частоти. Умова двофотонного резонансу виконана, якщо

$\delta_{3}=\delta_{1}+\frac{1}{2}\left(S_{3}-S_{1}\right)$.

\section{4. Світлові зсуви та зв'язок метастабільних станів}

Обчислення констант $S_{1}, S_{3}$ і $R$ проведемо для гаусового спектра поля (2) з великою кількістю спектральних компонент. Нехай також $n_{1}$ і $n_{3}$ значно менші за $n_{0}, n_{1} \ll n_{0}, n_{3} \ll n_{0}$. Тоді маємо

$a_{n+n_{j}}=\exp \left(-\frac{n^{2}}{2 n_{0}^{2}}\right)\left[1-\frac{n n_{j}}{n_{0}^{2}}-\frac{n_{j}^{2}}{2 n_{0}^{2}}+\right.$

$\left.+\frac{n_{j}^{2} n\left(n+n_{j}\right)}{2 n_{0}^{4}}-\frac{n^{3} n_{j}^{3}}{6 n_{0}^{6}}\right]+\ldots$

де $j=1,3 \mathrm{i}$

$S_{j}=-\frac{n_{j} \sqrt{\pi} \Omega_{j 0}^{2}}{n_{0} \varpi}\left(1-\frac{2 n_{j}^{2}}{3 n_{0}^{2}}\right)$.

Очевидно, $n_{3}$ і $n_{1}$ відрізняються на ціле число $N$, яке визначається відношенням $\omega_{12}-\omega_{32}=\omega_{13}$ до $\varpi$,

$n_{3}=n_{1}-N$

Уведемо двофотонне відстроювання

$\delta=\omega_{13}-N \varpi=\delta_{1}-\delta_{3}$,

де ціле $N$ вибираємо так, щоб мінімізувати $|\delta|$. Тоді

$\delta=\frac{1}{2}\left(S_{1}-S_{3}\right)$

показує, настільки резонанс КПН відстроєний від точного двофотонного резонансу. Цей зсув мінімальний, якщо

$n_{1}=\left[\frac{\Omega_{30}^{2} N}{\Omega_{30}^{2}-\Omega_{10}^{2}}\left(1-\frac{2 \Omega_{10}^{2} N^{2}\left(\Omega_{10}^{2}+\Omega_{30}^{2}\right)}{3 n_{0}^{2}\left(\Omega_{30}^{2}-\Omega_{10}^{2}\right)^{2}}\right)\right]$. 
У цьому випадку

$n_{3}=\left[\frac{\Omega_{10}^{2} N}{\Omega_{30}^{2}-\Omega_{10}^{2}}\left(1-\frac{2 \Omega_{30}^{2} N^{2}\left(\Omega_{10}^{2}+\Omega_{30}^{2}\right)}{3 n_{0}^{2}\left(\Omega_{30}^{2}-\Omega_{10}^{2}\right)^{2}}\right)\right]$.

Тут квадратні дужки показують, що обчислюється ціла частина виразу, оскільки $n_{1}$ - ціле. У випадку однакових матричних елементів дипольних моментів переходу, коли $\Omega_{30}^{2}=\Omega_{10}^{2}$, світловий зсув двофотонного резонансу описується виразом

$\delta_{3}-\delta_{1}=\frac{N \sqrt{\pi} \Omega_{10}^{2}}{2 n_{0}^{2} \varpi}$

Для $\varphi_{n}=0$ знаходимо $3(26)$ i (28)

$R=\frac{\Omega_{10} \Omega_{30}\left(n_{1}+n_{3}\right)}{2 n_{0} \varpi}$.

Порівнюючи (29) i (36), бачимо, що $S_{1}, S_{3}$ і $R-$ величини одного порядку.

Оскільки $n_{1}+n_{3} \ll n_{0}$, а $\Omega_{10}, \Omega_{30} \ll \varpi$, зв'язок метастабільних станів між собою дуже малий порівняно зі зв'язком метастабільних станів зі збудженим. За умови $n_{1}=-n_{3}$, тобто, коли частота спектральної компоненти з максимальною інтенсивністю $\omega=\frac{1}{2}\left(\omega_{12}+\omega_{32}\right)$, зв'язок метастабільних станів відсутній.

\section{5. Аналог стану когерентного полонення населеності у поліхроматичному полі}

Як видно з ефективного гамільтоніана (23), стани $|1\rangle$ i $|3\rangle$ у загальному випадку пов'язані між собою полем. При $R=0$ ефективний гамільтоніан (23) збігається з гамільтоніаном атома у біхроматичному полі. У цьому випадку за умови двофотонного резонансу в один з власних станів гамільтоніана, а саме, у стан з нульовим власним значенням, не входить збуджений стан $|2\rangle[12,13]$. Оскільки, як було показано у попередньому розділі, величина $R$ мала порівняно з частотами Рабі, за умови двофотонного резонансу слід чекати невеликого заселення збудженого стану в одному із власних станів ефективного гамільтоніана (23). Знайдемо цей власний стан. Виберемо $\delta_{1}=S_{1} / 2, \delta_{3}=S_{3} / 2$ і вважатимемо, що виконана умова $\varphi_{n}=0$. Стандартні обчислення дають рівняння для власних значень $\hbar \lambda$ гамільтоніана:

$2 \lambda\left(2 \lambda-\Omega_{0}\right)\left(2 \lambda+\Omega_{0}\right)+4\left(S_{1}+S_{3}\right) \lambda^{2}-$

$-\Omega_{0}^{2} R \sin 2 \theta-R^{2}\left(S_{1}+S_{3}+2 \lambda\right)=0$.
Тут введено

$\theta=\operatorname{arctg} \frac{\Omega_{1, s}}{\Omega_{3, s}}, \quad \Omega_{0}=\sqrt{\Omega_{1, s}^{2}+\Omega_{3, s}}$.

У нульовому наближенні за $R \mathrm{i} S_{1}+S_{3}$ з (37) випливає

$\lambda \approx 0$,

$\lambda_{ \pm} \approx \pm \frac{1}{2} \Omega_{0}$

Власне значення (39) відповідає стану когерентного полонення населеності. Уточнимо його і розглянемо власний стан, який йому відповідає. У першому наближенні з (37) знаходимо

$\lambda=-R \sin \theta \cos \theta=-R \frac{\Omega_{1, s} \Omega_{3, s}}{\Omega_{1, s}^{2}+\Omega_{3, s}^{2}}$.

Друге наближення нічого до (41) не додає. Хоч третє наближення отримати й нескладно, ми його не наводимо, оскільки для отриманих тут результатів воно несуттєве. Відповідний (41) власний стан гамільтоніана має вигляд

$\psi=\frac{\Omega_{0}}{\sqrt{\Omega_{0}^{2}+R^{2} \cos ^{2} 2 \theta}}\left(\begin{array}{c}-\cos \theta \\ \frac{R}{\Omega_{0}} \cos 2 \theta \\ \sin \theta\end{array}\right)$.

Як бачимо, населеність збудженого стану у власному стані (42) гамільтоніана мала і є величиною порядку $\left(\Omega_{0} / \varpi\right)^{2}$.

\section{6. Резонанси когерентного полонення населеності у поліхроматичному полі}

Виходячи $з$ ефективного гамільтоніана атома в поліхроматичному полі (23), на перший погляд можна чекати, що зсув мінімуму флуоресценції атома відносно двофотонного резонансу визначається різницею світлових зсувів першого та третього станів атома. На відміну від звичайного формування резонансу когерентного полонення населеності у біхроматичному полі, коли поле пов'язуе стани $|1\rangle,|2\rangle$ i $|3\rangle,|2\rangle$, гамільтоніан (23) вказує, що полем пов'язані також стани $|1\rangle,|3\rangle$. Такий зв'язок аналогічний до зв'язку між осциляторами, що, як відомо з [23], приводить до зсуву їх власних частот. Таким чином, є потреба проаналізувати, до яких наслідків веде наявність члена $R$ у ефективному гамільтоніані. 
Для аналізу залежності флуоресценції від двофотонного відстроювання використаємо рівняння для матриці густини. Взаємодія атома $з$ полем враховується гамільтоніаном (23), і нам лишається додати вплив релаксаційних процесів на еволюцію матриці густини. Застосовування формалізму ефективного гамільтоніана правомірне, коли різниця сусідніх спектральних компонент поліхроматичного поля значно перевищує швидкість релаксаційних процесів.

Вважатимемо, що атом зі збудженого стану $|2\rangle$ переходить у результаті спонтанного випромінювання в стан $|1\rangle$ зі швидкістю $\gamma_{1}$, а у стан $|3\rangle$ зі швидкістю $\gamma_{3}$. Крім того, релаксаційні процеси приводять до повільної, зі швидкістю $\gamma_{0}$, значно меншою, ніж $\gamma_{1}+\gamma_{3}$, релаксації когерентності $\rho_{13}$. У результаті рівняння для матриці густини мають вигляд

$\frac{d}{d t} \rho_{11}=\frac{i}{2} \Omega_{1} \rho_{12}-\frac{i}{2} \Omega_{1} \rho_{21}+\frac{i}{2} R\left(\rho_{13}-\rho_{31}\right)+\gamma_{1} \rho_{22}$,

$\frac{d}{d t} \rho_{12}=\frac{i}{2}\left(2 \delta_{1}-2 S_{1}-S_{3}\right) \rho_{12}+\frac{i}{2} \Omega_{1}\left(\rho_{11}-\rho_{22}\right)-$

$-\frac{i}{2} R \rho_{32}+\frac{i}{2} \Omega_{3} \rho_{13}-\frac{1}{2}\left(\gamma_{1}+\gamma_{3}\right) \rho_{12}$

$\frac{d}{d t} \rho_{13}=\frac{i}{2}\left(2 \delta_{1}-2 \delta_{3}+S_{3}-S_{1}\right) \rho_{13}+$

$+\frac{i}{2} R\left(\rho_{11}-\rho_{33}\right)+\frac{i}{2} \Omega_{3} \rho_{12}-\frac{i}{2} \Omega_{1} \rho_{23}-\gamma_{0} \rho_{13}$,

$\frac{d}{d t} \rho_{23}=\frac{i}{2}\left(S_{1}+2 S_{3}-2 \delta_{3}\right) \rho_{23}-\frac{i}{2} \Omega_{1} \rho_{13}+$

$+\frac{i}{2} \Omega_{3}\left(\rho_{22}-\rho_{33}\right)-\frac{i}{2} R \rho_{21}-\frac{1}{2}\left(\gamma_{1}+\gamma_{3}\right) \rho_{23}$,

$\frac{d}{d t} \rho_{33}=\frac{i}{2} \Omega_{3}\left(\rho_{32}-\rho_{23}\right)+\frac{i}{2} R\left(\rho_{31}-\rho_{13}\right)+\gamma_{3} \rho_{22}$,

$\rho_{n m}=\rho_{m n}^{*}, \quad n, m=1,2,3, \quad \rho_{11}+\rho_{22}+\rho_{33}=1$.

Для скорочення позначень ми не пишемо однаковий додатковий індекс $s$ біля частот Рабі.

Щоб оцінити сигнал флуоресценції, необхідно знайти вираз для населеності $\rho_{22}$ збудженого стану. Ширина резонансу КПН мала, коли частоти Рабі $\Omega_{1}, \Omega_{3}$ є величиною порядку $\gamma_{0}$. Як видно з виразів (29) і (36), світлові зсуви і частота $R$, що описує зв'язок станів $|1\rangle$ і $|3\rangle$, малі у порівнянні з частотами Рабі. Останні малі при зіставленні з $\gamma_{1}, \gamma_{3}$. Таким чином, вважаємо $R / \Omega_{j} \ll 1, \quad S_{j} / \Omega_{j} \ll 1, \quad \Omega_{j} \ll \gamma_{1}+\gamma_{3}$,

$\Omega_{j} \sim \gamma_{0}, \quad j=1,3$.

За цих умов зсув максимуму населеності збудженого стану, яку ми знаходимо зі стаціонарного розв'язку рівнянь (43), мінімальний при

$\delta=\delta_{R}+\delta_{S}$,

де

$\delta_{R}=\Omega_{1} \Omega_{3} R \gamma_{0}\left(\Omega_{3}^{4} \gamma_{1}-\Omega_{1}^{4} \gamma_{3}\right)\left(\gamma_{1}+\gamma_{3}\right) \times$

$\times\left[\Omega_{1}^{2} \Omega_{3}^{2}\left(\Omega_{1}^{2}+\Omega_{3}^{2}\right)\left(\Omega_{1}^{2} \gamma_{3}+\Omega_{3}^{2} \gamma_{1}\right)-\right.$

$\left.-\left(\Omega_{1}^{2}-\Omega_{3}^{2}\right)\left(\Omega_{1}^{2} \gamma_{3}-\Omega_{3}^{2} \gamma_{1}\right)\left(\gamma_{1}+\gamma_{3}\right)^{2} R^{2}\right]^{-1}$.

За умов (44) для досить широкого спектра лазерного випромінювання, коли $\omega_{13} / n_{0} \varpi \ll \varpi /\left(\gamma_{1}+\gamma_{3}\right)$, другий доданок у квадратних дужках (46) значно менший за перший, і тоді за порядком величини $\delta_{R} \sim$ $\left(\gamma_{1}+\gamma_{3}\right) R / \gamma_{0}$. У виразі (45), як правило, другий доданок відіграє визначальну роль у тих частинних випадках, коли перший малий, наприклад, при $R=0$. Тоді

$\delta_{S}=\frac{1}{2}\left(S_{1}-S_{3}\right)$.

Отриманий вираз для зсуву резонансу справедливий у випадку комірки без буферного газу, коли швидкість релаксації атомів у збудженому стані визначається спонтанним випромінюванням, і всі швидкості релаксації значно менші за $\varpi$. За наявності буферного газу швидкість релаксації оптичних когерентностей значно перевищує $\varpi$, тому взаємодію атома 3 поліхроматичним полем вже не можна характеризувати ефективним гамільтоніаном. Такий випадок проаналізовано у роботі [22].

Якщо ширина спектра випромінювання значно перевищує $\omega_{13}$, частоти Рабі спектральних компонент, резонансних до атомного переходу, дуже мало відрізняються від частот Рабі компоненти з максимальною інтенсивністю. Беручи до уваги те, що вони пропорційні дипольному моменту відповідного переходу, 
а його квадрату пропорційна імовірність переходу зі збудженого стану у стан $|1\rangle$ чи $|3\rangle$, нескладно отримати

$$
\frac{\Omega_{1}^{2}}{\gamma_{1}}=\frac{\Omega_{3}^{2}}{\gamma_{3}},
$$

і (46) набуває вигляду

$\delta_{R}=\frac{\gamma_{3}-\gamma_{1}}{2 \Omega_{1} \Omega_{3}} \gamma_{0} R$

Таким чином, $\delta_{R}=0$, якщо $\gamma_{3}=\gamma_{1}$. Тоді зсув резонансу (45) визначається доданком $\delta_{S}$.

На рис. 2 показано залежність населеності $\rho_{22}$ збудженого стану від двофотонного відстроювання $\delta$ від резонансу, отримана з розв'язку рівнянь (43) для матриці густини за умови (48). Як видно з рисунка, положення мінімуму населеності збудженого стану при $R \neq 0$, отримане 3 розв'язку рівнянь для матриці густини, добре узгоджується з результатом розрахунку за формулою (49). Мінімум кривої $\left(\delta_{S}=-0,005 \gamma_{0}\right)$, отриманий для випадку $R=0$, так само добре узгоджується 3 розрахунком за формулою (47), придатною в цьому випадкy.

\section{7. Висновки}

Ми показали, що при взаємодії трирівневого атома 3 поліхроматичним полем з еквідістантними частотами формується стан, аналогічний стану когерентного полонення населеності в біхроматичному полі. На відміну від випадку біхроматичного поля в нього входить, крім метастабільних станів, також незначна домішка збудженого стану, амплітуда якого тим менша, чим ширший спектр лазерного випромінювання. Ефективний гамільтоніан, який описує повільну, порівняно з періодом поля, зміну амплітуд імовірності заселеності станів атома, містить зв'язок між метастабільними станами. Наявність такого зв'язку приводить до зсуву резонансу когерентного полонення населеностей.

Цікавим могло б бути застосування розвинутої теорії до створення стандарту частоти на основі ансамблю холодних атомів чи іонів ${ }^{229} \mathrm{Th}$ [27]. Розщеплення основного стану ядра становить близько 7,6 еВ [28] (вакуумний ультрафіолет), час життя збудженого стану ядра близько години [29] свідчить про перспективність створення високоточного годинника на основі переходу у цьому ядрі.

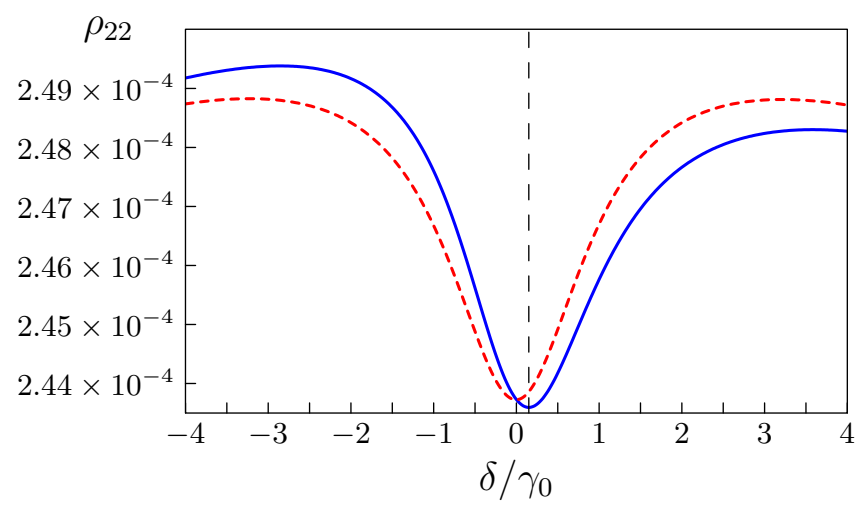

Рис. 2. Залежність населеності $\rho_{22}$ збудженого стану від двофотонного відстроювання $\delta$ від резонансу, отримана з розв'язку рівнянь (43) для матриці густини за умови (48). Параметри: $\Omega_{1}=\gamma_{0}, \Omega_{3}=2 \gamma_{0}, \gamma_{1}+\gamma_{3}=100 \gamma_{0}, S_{1}=0,01 \gamma_{0}, S_{3}=0,02 \gamma_{0}$, $\delta_{1}=0$. Для суцільної кривої $R=0,01 \gamma_{0}$, для пунктирної $R=0$. Вертикальна лінія показує положення мінімуму населеності збудженого стану $\left(\delta_{R}=0,15 \gamma_{0}\right)$, розрахованого за формулою (49)

Роботу виконано за проектом №Ф 40.2/039 Державного фонду фундаментальних досліджень, а також за темами НАНУ В136 та ВЦ139.

1. E. Arimondo and G. Orriols, Nuovo Cimento Lett. 17, 333 (1976).

2. G. Alzetta, A. Gozzini, L. Moi, and G. Orriols, Nuovo Cimento B Ser. 2 36, 5 (1976).

3. H.R. Gray, R.W. Whitley, and C.R. Stroud, Jr., Opt. Lett. 3, 218 (1978).

4. G. Orriols, Nuovo Cimento B Ser. 2 53, 1 (1979).

5. G. Alzetta, L. Moi, and G. Orriols, Nuovo Cimento B Ser. 2 52, 209 (1979).

6. O.A. Kocharovskaya and Ya.I. Khanin, Sov. Phys. JETP 63, 945 (1986).

7. M.B. Gornyı̆, B.G. Matisov, and Yu.V. Rozhdestvenskiı̌, Sov. Phys. JETP 68, 728 (1989).

8. K.-J. Boller, A. Imamoglu, and S.E. Harris, Phys. Rev. Lett. 66, 2593 (1991).

9. S.E. Harris, Phys. Today 50, 36 (1997).

10. J. Oreg, F.T. Hioe, and J.H. Eberly, Phys. Rev. A 29, 690 (1984).

11. U. Gaubatz, P. Rudecki, M. Becker, S. Schiemann, M. Kulz, and K. Bergmann, Chem. Phys. Lett. 149, 463 (1988).

12. K. Bergmann, H. Theur, and B.W. Shore, Rev. Mod. Phys. 70, 1003 (1998).

13. N.V. Vitanov, T. Halfmann, B.W. Shore, and K. Bergmann, Ann. Rev. Phys. Chem. 52, 763 (2001). 
14. S. Knappe, R. Wynands, J. Kitching, H.G. Robinson, and L. Hollberg, J. Opt. Soc. Am. B 18, 1545 (2001).

15. A. Aspect, E. Arimondo, R. Kaiser, N. Vansteenkiste, and C. Cohen-Tannoudji, Phys. Rev. Lett. 61, 826 (1988).

16. G. Alzetta, S. Gozzini, A. Lucchesini, S. Cartaleva, T. Karaulanov, C. Marinelli, and L. Moi, Phys. Rev. A 69, 063815 (2004).

17. V.A. Sautenkov, Yu.V. Rostovtsev, C.Y. Ye, G.R. Welch, O. Kocharovskaya, and M.O. Scully, Phys. Rev. A 71, 063804 (2005).

18. L. Arissian and J.-C. Diels, Opt. Commun. 264, 169 (2006)

19. Yu.V. Vladimirova, B.A. Grishanin, V.N. Zadkov, V. Biancalana, G. Bevilacqua, Y. Dancheva, and L. Moi, Zh. Èksp. Teor. Fiz. 103, 528 (2006).

20. М. Аузіньш, Р.А. Маліцький, І.В. Мацнєв, А.М. Негрійко, В.І. Романенко, В.М. Ходаковський, Л.П. Яценко, УФЖ 54, 975 (2009).

21. L.P. Yatsenko, B.W. Shore, and K. Bergmann, Opt. Commun. 236, 183 (2004).

22. V.I. Romanenko, A.V. Romanenko, L.P. Yatsenko, G.A. Kazakov, A.N. Litvinov, B.G. Matisov, and Yu.V. Rozhdestvensky, J. Phys. B 43, 215402 (2010).

23. Л.Д. Ландау, Е.М. Лифшиц, Механика (Наука, Главная редакция физ.-мат. литературы, Москва, 1973), 208 c.

24. M. Cashen, O. Rivoire, V. Romanenko, L. Yatsenko, and H. Metcalf, Phys. Rev. A 64, 063411 (2001).

25. V.I. Romanenko, A.V. Romanenko, and L.P. Yatsenko, J. Phys. B 44, 215402 (2011).

26. B.W. Shore, The Theory of Coherent Atomic Excitation (Wiley, New York, 1990).

27. E. Peik and Chr. Tamm, Europhys. Lett. 61, 181 (2003).

28. B.R. Beck, J.A. Becker, P. Beiersdorfer, G.V. Brown, K.J. Moody, J.B, Wilhelmy, F.S. Porter, C.A. Kilbourne, and R.L. Kelly, Phys. Rev. Lett. 98, 142501 (2007).

29. E.V. Tkalya, A.N. Zherykhin, and V.I. Zhudov, Phys. Rev. C 61, 064380 (2000).

Одержано 22.08.11
АНАЛОГ СОСТОЯНИЯ КОГЕРЕНТНОГО ПЛЕНЕНИЯ
НАСЕЛЕННОСТЕЙ В ПОЛИХРОМАТИЧЕСКОМ ПОЛЕ

В.И. Романенко, А.В. Романенко, Л.П. Яценко

$\mathrm{P}$ е $з$ ю м е

Теоретически исследовано взаимодействие трехуровневого атома с полихроматическим полем с эквидистантными спектральными компонентами ( $\Lambda$-схема взаимодействия с полем). Показано, что взаимодействие атома с таким полем сводится к взаимодействию с бихроматическим полем с дополнительными световыми сдвигами частот переходов и дополнительной, пропорциональной интенсивности поля, связи нижних уровней атома. Наличие этой связи позволяет говорить о когерентном пленении населенностей лишь приближенно, поскольку в общем случае произвольных дипольных моментов переходов темное состояние не собственное состояние эффективного гамильтониана. Рассмотренная модель дает простую теоретическую интерпретацию формирования состояния атома, близкого к состоянию когерентного пленения населенностей в поле излучения фемтосекундного лазера.

\section{ANALOG OF THE COHERENT POPULATION} TRAPPING STATE IN A POLYCHROMATIC FIELD

\section{V.I. Romanenko ${ }^{1}$, A.V. Romanenko ${ }^{2}$, L.P. Yatsenko ${ }^{1}$}

${ }^{1}$ Institute of Physics, Nat. Acad. of Sci. of Ukraine

(46, Prosp. Nauky, Kyiv 03028,Ukraine; e-mail:vr@iop.kiev.ua), ${ }^{2}$ Taras Shevchenko National University of Kyiv

(2, Prosp. Academician Glushkov, Kyiv 03022, Ukraine)

$\mathrm{S} u \mathrm{~mm}$ a r y

The interaction between a three-level atom and a polychromatic field with an equidistant spectrum $(\Lambda$-scheme of the atom-field interaction) has been studied theoretically. It is shown that the interaction of an atom with such a field can be reduced to its interaction with a bichromatic field with additional light shifts of transition frequencies and an additional coupling of the lower atomic levels, which is proportional to the field intensity. Owing to this coupling, the idea of the coherent population trapping can be considered only as an approximation, because the dark state is not an eigenstate of the effective Hamiltonian in the general case of arbitrary dipole moments. The analyzed model gives a simple theoretical interpretation for the formation of the atomic state, which is close to the coherent population trapping, in the radiation field of a femtosecond laser. 